\title{
El impacto de la medicina de precisión en el currículo médico.
}

\section{Precision medicine Impact on the medical syllabus.}

Las ciencias de la salud, entre ellas la medicina, ha resuelto los problemas vinculados al proceso salud enfermedad de acuerdo al paradigma ${ }^{\mathrm{i}}$ conceptual de un momento histórico determinado, esto permitió establecer una forma de interpretar la enfermedad y de intervenir en la prevención y la patología para resolver los problemas de salud de los individuos y sus comunidades.

Estos paradigmas fueron cambiando desde el conocimiento "científico" predominante en cada periodo. En épocas ancestrales se explicaron la salud y la enfermedad desde los conceptos mágicos teúrgicos, por lo tanto, el aprendizaje dependía de "seres supremos ", se entremezclaban magos, sacerdotes y "médicos" con un proceso "enseñanza aprendizaje” casi inexistente.

Cuando Hipócrates es capaz de demostrar que la medicina podía ser incluida en las Artes Liberales Griegas, por lo tanto, enseñada y aprendida, aparecen las primeras escuelas de medicina, en templos sagrados (Asclepeion) destinados a la recuperación de la salud. Se explica el proceso salud enfermedad desde la Eucrasia y Discrasia, equilibrio y desequilibrio, concepto tan preciado para la antigua cultura griega ${ }^{1}$.

En el siglo XV, denominado Revolución científica, donde se impone los criterios de la ciencia moderna de reproductibilidad y verificación de los resultados, se modifica de manera importante la enseñanza de la medicina, pero ante la imposibilidad de acceder al conocimiento de las estructuras moleculares y su rol en la fisiopatogenia, se centra el estudio en una anatomía macroscópica y microscópica profunda. Esta es el área del conocimiento a partir de la cual se desarrollan los planes de estudio hasta el siglo XVIII. A partir de esta época el avance de los "saberes son en tal magnitud que la "ciencia médica" adhiere al paradigma Enciclopedista predominante en este momento cultural.

Revista Methodo: Investigación Aplicada a las Ciencias Biológicas. Facultad de Medicina. Universidad Católica de Córdoba. Jacinto Ríos 571 Bo Gral. Paz. X5004FXS. Córdoba. Argentina. Tel.: (54) 3514517299 
Como consecuencia, a comienzos del siglo XX por la magnitud de los conocimientos científicos que obliga a la especialización y al enciclopedismo, aparece el denominado informe Flexner, escrito por Abraham Flexner en 1910 para definir la educación médica en los Estados Unidos y Canadá, cuyo fundamento principal es "La formación médica debe apoyarse sobre una sólida base científica". Evidentemente esto vuelve a impactar en el currículo de la carrera de medicina, donde el cumulo de saberes enciclopédicos son el punto crítico para el hacer médico².

Desde fines del siglo XX, donde se comienza a imponer la biotecnología en la producción de conocimiento y en la aplicación de estos en los pacientes y sus comunidades, aparece en el escenario un paradigma para la atención médica moderna, como un proceso proactivo e individualizado, denominado "medicina de precisión o personalizada ii ", llamado así por profundo conocimiento molecular de la fisiopatogenia que permiten dar respuesta a los problemas de salud, combinando diagnóstico de precisión y tratamiento personalizado ${ }^{3}$.

Evidentemente este paradigma que se impone en todos los campos de la medicina a partir del siglo XXI, por decir un año diríamos 2010, debe tener su impacto en el desarrollo de los planes de estudios.

Los estudiantes deben acceder a los conocimientos a partir de un currículo integrado, que se desarrolla desde el cómo será el hacer médico en los próximos años. Los planes actuales plantean conceptualmente desintegración y desarticulación con la realidad científica de la medicina y la realidad socio cultural de los estudiantes de medicina, lo que obliga a su revisión.

Los estudiantes deben acceder a los conocimientos a partir de un currículo integrado, que se desarrolla desde el cómo será el hacer médico en los próximos años. Los planes actuales plantean conceptualmente desintegración y desarticulación con la realidad científica de la medicina y la realidad socio cultural de los estudiantes de medicina, lo que obliga a su revisión.

El enfoque tradicional de la medicina a nivel de metodología usa la evaluación de las propiedades visibles en la enfermedad y la salud, mientras que la medicina de precisión aplica la clasificación por riesgo, usa el big data, y hace vigilancia para la enfermedad preclínica. A nivel de intervención, la concepción tradicional, hace enfoque en la patología y la medicina personalizada se centra en el individuo, lo que tendrá elevado impacto en las estrategias terapéuticas ${ }^{3}$.

A esta realidad, se le agrega la capacidad del mundo de difundir el conocimiento a través de internet, donde todo está "al alcance de la mano", a tiempo real y urgente, tanto para los que cumplimos el rol de médicos y docentes como para nuestros pacientes y estudiantes.

Estos conceptos y conocimientos nuevos, que actualmente genera un nuevo saber cada noventa minutos, obliga a modificar en los planes de estudios la forma de enseñar y aprender las ciencias de la salud.

Revista Methodo: Investigación Aplicada a las Ciencias Biológicas. Facultad de Medicina. Universidad Católica de Córdoba. Jacinto Ríos 571 Bo Gral. Paz. X5004FXS. Córdoba. Argentina. Tel.: (54) 351 4517299 / Correo: methodo@ucc.edu.ar / Web: methodo.ucc.edu.ar | EDITORIAL Rev. Methodo 2019;4(2):31-33 
Al viejo concepto personalista "no hay enfermedades sino enfermos" se le debe incluir, hoy más que nunca, diagnósticos de precisión y tratamientos personalizados que requerirá una mejor comprensión de biomarcadores, fenotipos, endotipos, genotipos.

No debe existir duda de que los currículos de la carrera de medicina y de sus posgrados deben ajustarse a esta realidad, dejando lo tradicional y creando planes integrados que le permitan a los estudiantes ser médicos acordes a las exigencias del siglo XXI con una mirada "personalizada ${ }^{\mathrm{ii}}$ " e "Integrada" del paciente.

Bibliografía

1. Apuntes Historia de la Medicina - Escuela de Medicina (UC). [disponible en: publicacionesmedicina.uc.cl/Historia Medicina/Indice.html].

2. Pinzón Flórez CE. Los grandes paradigmas de la educación médica en Latinoamérica Acta Med Colomb 2008; 33: 33-41

3. Agache I, Akdis CA. Precision medicine and phenotypes, endotypes, genotypes, regiotypes, and theratypes of allergic diseases J Clin Invest. 2019;129(4):1493-1503. https://doi.org/10.1172/JCI124611

Nota: ${ }^{i}$ Kuhn Thomas, en La estructura de las revoluciones científicas, 1962. Definición de Paradigma: El marco de referencias conceptuales que utiliza la comunidad científica y sirve de modelo útil para estudiar problemas y elaborar soluciones.

${ }^{i i} \mathrm{NIH}$ - National Cancer Institute: Tipo de medicina que usa la información de los genes, las proteínas y el ambiente de una persona para prevenir, diagnosticar y tratar una enfermedad. También se llama medicina personalizada.

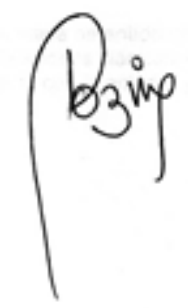

Alejandro Lozano

Editor. 